\title{
PAH Analytics in New Polish Reference Material
}

\author{
Anna Kiełbasa, Bogusław Buszewski* \\ Chair of Environmental Chemistry and Bioanalytics, Faculty of Chemistry, \\ Nicolaus Copernicus University, Gagarin 7, 87-100 Torun, Poland
}

Received: April 2, 2015

Accepted: May 14, 2015

\begin{abstract}
A significant number of polycyclic aromatic hydrocarbon (PAH) extraction methods exists. While studying new reference materials, accelerated solvent extraction (ASE) with the use of a dichloromethane-acetone mixture turned out to be the best extraction method for six selected compounds representing the PAH group. This method allowed the recovery ranging from 90 to $115 \%$ and repeatability varying from 0.74 to 1.6 . In order to validate the PAH extraction and determination method, liquid chromatography with a fluorescence detector (HPLC/FLD) and gas chromatography-mass spectrometry (GC/MS) were applied. The combination of the two methods enabled the achievement of satisfactory results both in soil being the matrix for the new material and in a new Polish candidate for a reference material. The development and validation of the method for PAH extraction and determination in soil was necessary for the purposes of further certification tests aimed at designating the certified value of the new reference material.
\end{abstract}

Keywords: certified reference material, soil, PAH, HPLC/FLD, GC/MS

\section{Introduction}

Even more frequently than they used to, analysts face the problem of the quantitative determination of substances present at very low concentrations and in complicated matrices. These substances can be xenobiotics - even trace amounts of which can considerably affect human organisms. In such kinds of analysis, it is particularly important to provide the adequate quality of the process and obtain reliable results (quality assurance QA and quality control QC) [1-3]. Therefore, the task becomes more difficult when the concentration of a substance tested decreases and the complexity of the matrices composition increases [4-6]. The quality of our life depends on the reliability of the measurement results (physical as well chemical quantities), which often influence our decisions. The results obtained with an adequate precision allow drawing appropriate con-

*e-mail: bbusz@chem.umk.pl clusions from our scientific work. The factors influencing the quality of measurement results obtained are presented in Fig. 1.

Each of the factors is closely related with reference materials (RM) and certified reference materials (CRM). A reference material should be considered as a material homogeneous and stable enough from one or more specific properties viewpoints and prepared in order to be applied in the measurement process. The reference material - one or more properties of which were metrologically characterized with a recognized procedure, and which is approved with a certificate specifying the values for the denoted properties and associated uncertainty, as well as confirming metrological traceability - is called a certified reference material [3, 7]. Reference materials can be categorized according to a few criteria [7-9]. The basic classification of reference materials is shown in Fig. 2.

All the reference material guidelines covering terminology, production methods, certification, quality assurance, 


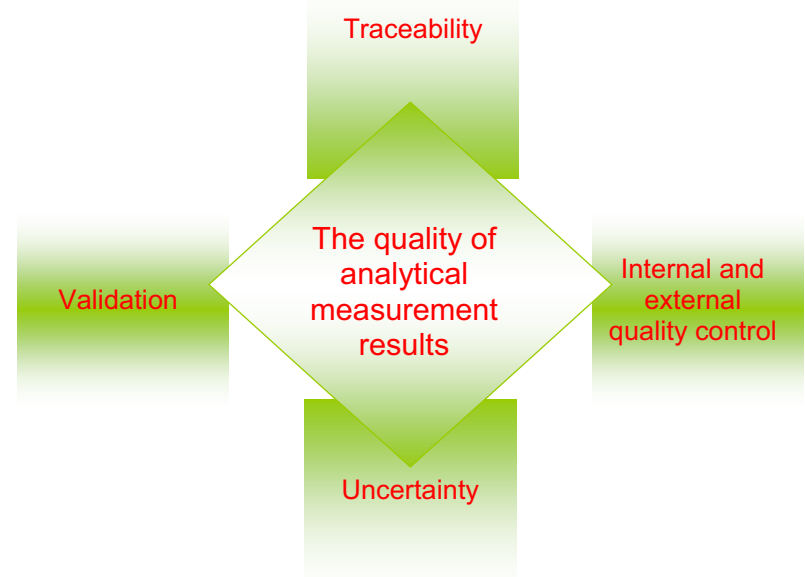

Fig. 1. Factors influencing the quality of measurement results.

and application are contained in ISO guides No. 30 to 35 [3]. Certified reference materials have to meet four basic criteria:

- Stability

- Homogeneity

- Analyte content determined with the required precision and accuracy

- Cohesive documentation - certificate $[3,6,7]$

Reference materials are developed in a multi-stage, complex process which is stretched over a few years' time. The organization of research carried out in a number of lab- oratories in order to perform the certification process is one of the above mentioned stages. The process is based on both determining the certified value of the new reference material with the use of validated measurement methods, as well as providing traceability. The process is carried out in selected laboratories $[3,7]$.

In the new Polish candidate for reference material, six compounds belonging to the PAH group were determined: pyrene, benzo(a)anthracene, benzo(b)fluoranthene, benzo(k)fluoranthene, benzo(a)pyrene, and indeno(1,2,3cd)pyrene. In this article, attempts to find the best PAH extraction method from the soil samples and then the validation process of the chosen method were described. With the use of the validated method, the PAH contents in both the new candidate for reference material and uncontaminated soil constituting its matrix were determined. It is a preparation stage for further certification examinations.

\section{Experimental Procedures}

\section{Reagents and Materials}

The certified standard of the six PAHs (pyrene, benzo(a)pyrene, benzo(b)fluoranthene, benzo(k)fluoranthene, benzo(a)anthracene, and indeno(1,2,3-cd)pyrene) in acetonitrile was supplied by LGC Standards. The concentration of each compound was declared $10 \mathrm{ng} / \mathrm{mL}$. This solution was stored at $+4^{\circ} \mathrm{C}$. For optimization, analysis of the PAH in soil was supplied by CRM 141 (Table 1).

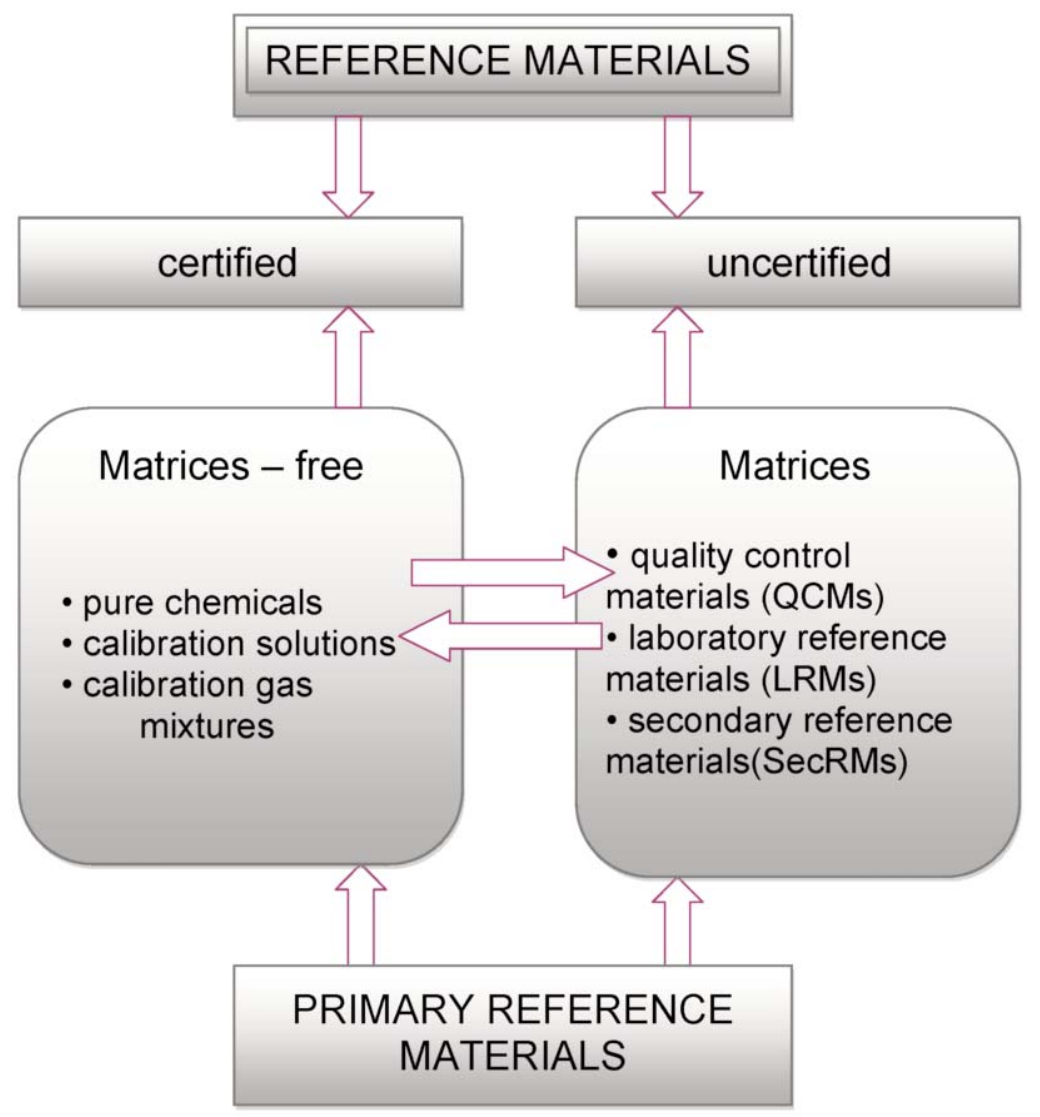

Fig. 2. Classification of reference materials. 
Table 1. Concentrations of PAH in CRM141 (according to the certificate).

\begin{tabular}{|l|c|c|}
\hline \multicolumn{1}{|c|}{ Compounds } & Concentration $[\mu \mathrm{g} / \mathrm{kg}]$ & $\mathrm{SD}$ \\
\hline Pyrene & 420 & 42.1 \\
\hline Benzo(a)anthracene & 94.4 & 5.56 \\
\hline Benzo(b)fluoranthene & 240 & 12.9 \\
\hline Benzo(k)fluoranthene & 341 & 35.6 \\
\hline Benzo(a)pyrene & 128 & 8.71 \\
\hline Indeno(1,2,3-cd)pyrene & 240 & 23.1 \\
\hline
\end{tabular}

This material was supplied by Sigma Aldrich and was stored at $+4^{\circ} \mathrm{C}$. The candidate for the new reference materials and its matrix were kept in closed, dark glass bottles. Each of them contained 50 grams of soil. These materials were stored at $4^{\circ} \mathrm{C}$. The materials were powdered and homogenized. Dichloromethane, acetone, hexane, cyclohexane, 2-propanol, methanol, petroleum ether, and acetonitrile were supplied by Avantor Performance Materials Poland S.A. All the reagents were of HPLC grade. Anhydrous sodium sulfate was supplied by Avantor Performance Materials Poland S.A. Water used was obtained from a MilliQ system. Nitrogen was of purity higher than $99 \%$. The sample was filtered through syringe filters (PTFE, $13 \mathrm{~mm}$ diameter and $0.22 \mu \mathrm{m}$ pore size).

\section{Instruments and Equipment}

For extraction, an ultrasonic bath (VWR International, USA), a UW 2070 ultrasonic homogenizer (Bandelin Electronic GmbH \& Co. KG, Germany), an accelerated solvent extraction (ASE 100, Dionex), and a laboratory shaker (Edmund Bühler GmbH, Germany) were used.

For HPLC/FLD analysis, a liquid chromatograph (Agilent Technologies 1100 Series and 1260 Infinity) was used. The chromatograph was performed on a non-polar column YMC PAH $(250 \mathrm{~mm} \times 3.0 \mathrm{~mm} ; 5 \mu \mathrm{m})$ purchased from Bujno Chemicals. The analytes were determined by gradient elution with an acetonitrile-water binary system and subsequent fluorescence detection set at the appropriate excitation and emission wavelengths (Table 2). $5 \mu 1$ of the extract was injected. The column temperature was set at $30^{\circ} \mathrm{C}$. The mobile phase flowed at a rate of $1 \mathrm{~mL} / \mathrm{min}$. The following gradient program is recommended: $0-5 \mathrm{~min}$. 50\% acetonitrile, 5-20 min. 50-100\% acetonitrile, 20-28 min. $100 \%$ acetonitrile, $28-32 \mathrm{~min}$. 100-50\% acetonitrile, and $32-45 \mathrm{~min}$. $50 \%$ acetonitrile.

The gas chromatograph was fitted with a selective mass detector (Agilent Technologies $6890 \mathrm{~N}$ and 5975 Series, respectively) and a $30 \mathrm{~m} \times 0.25 \mathrm{~mm} \times 0.25 \mu \mathrm{m}$ capillary column (ZB-5MS, Phenomenex). An aliquot $(1 \mu \mathrm{l})$ of the acetonitrile extract was injected. The GC-oven was temperature-programmed for an initial temperature of $50^{\circ} \mathrm{C}$, held for $1 \mathrm{~min}$, increased to $190^{\circ} \mathrm{C}$ for $9.5 \mathrm{~min}$, held for $2 \mathrm{~min}$, and then raised to $300^{\circ} \mathrm{C}$ for $37.5 \mathrm{~min}$. The injector and
Table 2. The excitation and emission wavelengths for six PAHs.

\begin{tabular}{|c|c|c|}
\hline Compounds & $\begin{array}{c}\text { Excitation } \\
\text { wavelengths }\end{array}$ & $\begin{array}{c}\text { Emission } \\
\text { wavelengths }\end{array}$ \\
\hline Pyrene & $260 \mathrm{~nm}$ & $420 \mathrm{~nm}$ \\
\hline Benzo(a)anthracene & $265 \mathrm{~nm}$ & $385 \mathrm{~nm}$ \\
\hline Benzo(b)fluoranthene & \multirow{3}{*}{$305 \mathrm{~nm}$} & \multirow{3}{*}{$430 \mathrm{~nm}$} \\
\hline Benzo(k)fluoranthene & & \\
\hline Benzo(a)pyrene & & \\
\hline Indeno(1,2,3-cd)pyrene & $250 \mathrm{~nm}$ & $500 \mathrm{~nm}$ \\
\hline
\end{tabular}

mass selective detector temperature were set to $280^{\circ} \mathrm{C}$ and $300^{\circ} \mathrm{C}$, respectively. Helium was the carrier gas and flowed at a rate of $1.1 \mathrm{~mL} / \mathrm{min}$. A splitless injection mode was used in the analysis. The time of analysis was 30 minutes.

\section{Extraction PAH from Soil}

All the extracts were concentrated in a mild stream of nitrogen at a temperature not exceeding $30^{\circ} \mathrm{C}$. The final volume of each sample was $1 \mathrm{ml}$ and acetonitrile was the solvent. Prior to carrying out the chromatographic analysis, each sample was filtered out with the use of Teflon syringe filters.

The ultrasound-assisted extraction was the first method applied $[10,11]$. The extraction was performed with the use of five different solvents or their mixtures. The two-step extraction was carried out twice. In one sample, the analytes were extracted with the use of the first mixture. Next, the above-mentioned sample was treated with another mixture or a solvent. The extracts were put together. 1.0 $\mathrm{g}$ of the sample and $5 \mathrm{ml}$ of the solvent were used for each extraction. The extraction was conducted three times for 20 min. Each time, a new portion of the solvent was used. The extracts were concentrated and chromatographically analysed. The obtained results are presented in Table 3.

Another method applied was, once again, ultrasoundassisted extraction. In this case, an ultrasound homogenizer was additionally used. A $1.0 \mathrm{~g}$ sample was placed in a Teflon container and $5 \mathrm{ml}$ of the solvent were added. The extraction was carried out for $2 \mathrm{~min}$. with the percent duty cycle at $55 \%$. The applied tapered microtip ultrasonic probe was $3 \mathrm{~mm}(1 / 8$-inch) thick. The process was repeated three times and a new portion of the solvent was used each time. The extracts were collected and concentrated in the above-mentioned manner. The samples were chromatographically analysed (HPLC/FLD) and the obtained results are shown in Table 4.

The accelerated solvent extraction (ASE) was the third method used $[12,13]$. A few solvent mixtures were applied. A two-step extraction was tested. In the process, analytes were first extracted with one solvent, and then the same sample was extracted with another solvent. The resulting extracts were put together. The $1.0 \mathrm{~g}$ sample was carefully mixed with roast sand and placed in an extraction cell. 
Table 3. Recovery and reproducibility for extraction using an ultrasonic bath.

\begin{tabular}{|c|c|c|c|c|c|c|c|c|c|c|}
\hline \multirow[b]{2}{*}{ Solvent/compound } & \multicolumn{10}{|c|}{ Recovery \% } \\
\hline & $\begin{array}{c}\text { Dichloromethane: } \\
\text { acetone }(1: 1)+ \\
\text { hexane:acetone } \\
(1: 1)\end{array}$ & $\mathrm{SD}$ & $\begin{array}{c}\text { Dichloromethane }+ \\
\text { dichloromethane: } \\
\text { acetone }(1: 1)\end{array}$ & SD & $\begin{array}{l}\text { Acetone: } \\
\text { hexane } \\
(1: 1)\end{array}$ & $\mathrm{SD}$ & $\begin{array}{c}\text { Dichloro- } \\
\text { methane }\end{array}$ & $\mathrm{SD}$ & $\begin{array}{c}\text { Iso- } \\
\text { propanol }\end{array}$ & SD \\
\hline Pyrene & 73 & 15.0 & 66 & 9.1 & 56 & 8.3 & 92 & 10.0 & 44 & 12.0 \\
\hline Benzo(a)anthracene & 70 & 13.0 & 65 & 10.0 & 50 & 7.5 & 84 & 8.5 & 37 & 9.4 \\
\hline Benzo(b)fluoranthene & 65 & 8.6 & 67 & 7.2 & 54 & 8.4 & 90 & 6.0 & 41 & 9.8 \\
\hline Benzo(k)fluoranthene & 61 & 7.4 & 65 & 7.1 & 56 & 5.2 & 94 & 7.0 & 38 & 10.0 \\
\hline Benzo(a)pyrene & 30 & 4.7 & 29 & 3.9 & 28 & 6.9 & 49 & 7.9 & 20 & 7.8 \\
\hline Indeno(1.2.3-cd)pyrene & 61 & 8.1 & 67 & 7.4 & 53 & 7.1 & 92 & 8.0 & 29 & 9.1 \\
\hline
\end{tabular}

Table 4. Recovery and reproducibility for extraction using an ultrasonic homogenizer.

\begin{tabular}{|l|c|c|c|c|c|c|c|c|}
\hline \multirow{2}{*}{ Solvent/compound } & \multicolumn{7}{|c|}{ Recovery \% } & Michloromethane: \\
\cline { 2 - 10 } & $\begin{array}{c}\text { Hexane: } \\
\text { acetone (1:1) }\end{array}$ & SD & $\begin{array}{c}\text { SD } \\
\text { acetone (1:1) }\end{array}$ & Dichloromethane & SD & Methanol & SD \\
\hline Pyrene & 97 & 11 & 80 & 14 & 84 & 12.0 & 77 & 10.0 \\
\hline Benzo(a)anthracene & 93 & 9.3 & 81 & 7.8 & 95 & 8.5 & 76 & 7.5 \\
\hline Benzo(b)fluoranthene & 83 & 8.5 & 74 & 7.5 & 78 & 7.5 & 84 & 8.0 \\
\hline Benzo(k)fluoranthene & 76 & 7.1 & 71 & 8.0 & 75 & 7.3 & 80 & 6.0 \\
\hline Benzo(a)pyrene & 31 & 6.9 & 28 & 6.0 & 28 & 4.9 & 31 & 8.5 \\
\hline Indeno(1.2.3-cd)pyrene & 71 & 8.0 & 69 & 8.0 & 72 & 10.0 & 79 & 9.0 \\
\hline
\end{tabular}

The extraction ran at $100^{\circ} \mathrm{C}$ in three static cycles, 5 min each. The extract was then concentrated and analysed as previously. The obtained results are presented in Table 5.

All the results obtained by different extraction methods applied were confronted with the PAH determination method based on Standard Norm (PN-ISO 13877) with modification. $10 \mathrm{~g}$ of soil were placed in a conical flask. $100 \mathrm{ml}$ of acetone were added and the mixture was shak- en for $15 \mathrm{~min}$. Next, $50 \mathrm{ml}$ of petroleum ether was added and the mixture was shaken for $15 \mathrm{~min}$. After the removal of acetone and polar compounds by shaking with water twice, the obtained extract was dried with anhydrous sodium sulphate. Next, the extract was concentrated and the solvent was changed to acetonitrile. A chromatographic analysis was then performed. The results are shown in Table 6.

Table 5. Recovery and reproducibility for the ASE using different solvents.

\begin{tabular}{|l|c|c|c|c|c|c|c|c|}
\hline \multirow{2}{*}{ Solvent/compound } & \multicolumn{9}{|c|}{ Recovery \% } & Cyclohexane + & SD \\
& Hexane: & SD & $\begin{array}{c}\text { Dichloromethane: } \\
\text { acetone (1:1) }\end{array}$ & SD & Cyclohexane & SD & $\begin{array}{c}\text { dichloromethane: } \\
\text { acetone }(1: 1)\end{array}$ & $\begin{array}{c}\text { SD } \\
\text { Pyrene }\end{array}$ \\
\cline { 2 - 10 } & 99 & 3.7 & 99 & 1.6 & 90 & 7.1 & 87 & 1.5 \\
\hline Benzo(a)anthracene & 94 & 5.0 & 93 & 0.74 & 89 & 3.9 & 81 & 1.7 \\
\hline Benzo(b)fluoranthene & 107 & 5.9 & 115 & 1.3 & 96 & 3.8 & 95 & 0.98 \\
\hline Benzo(k)fluoranthene & 103 & 8.1 & 109 & 0.93 & 92 & 7.6 & 92 & 1.1 \\
\hline Benzo(a)pyrene & 86 & 1.9 & 90 & 1.2 & 70 & 2.6 & 89 & 1.7 \\
\hline Indeno(1.2.3-cd)pyrene & 111 & 6.6 & 115 & 1.5 & 92 & 6.9 & 97 & 1.5 \\
\hline
\end{tabular}



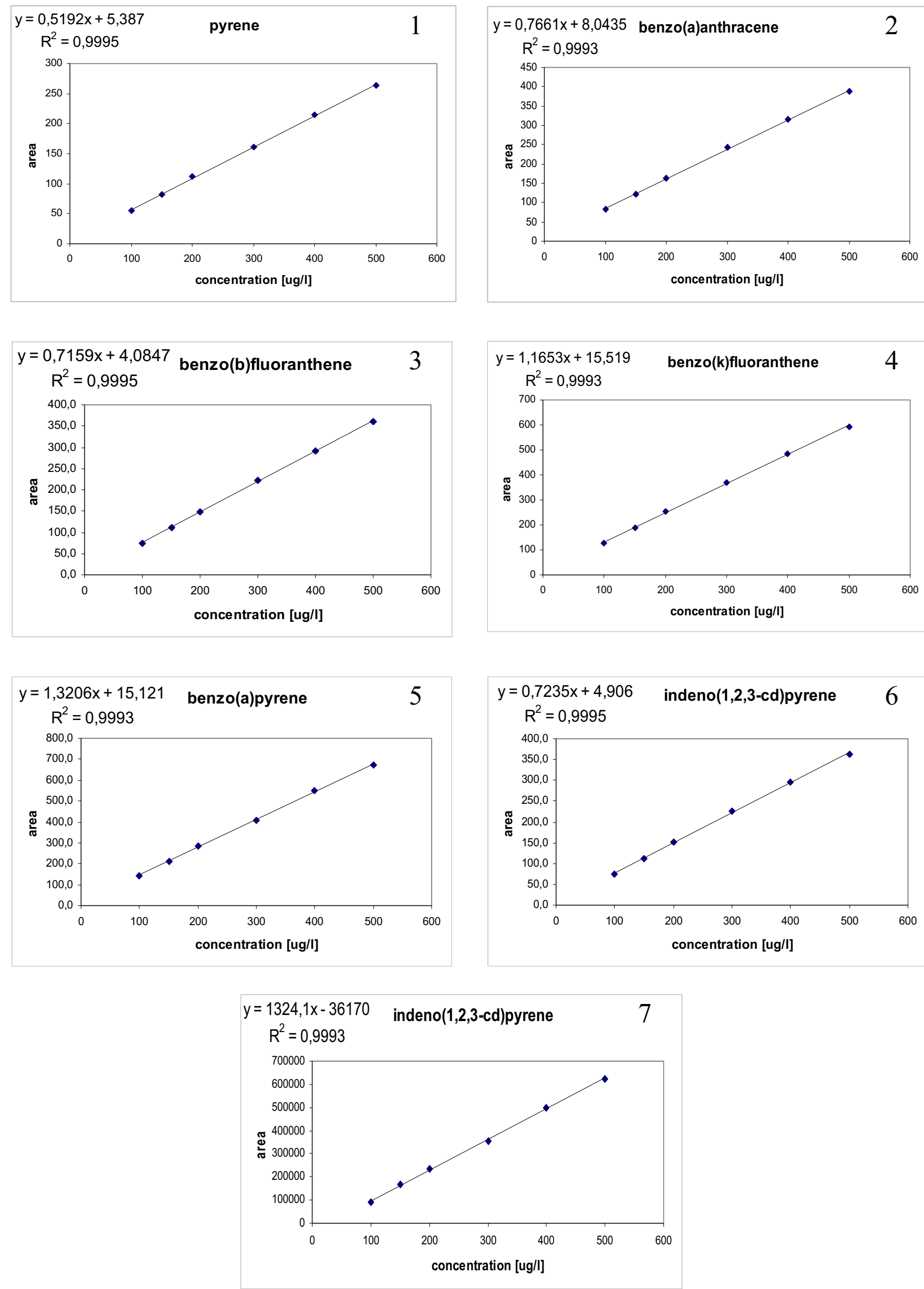

Fig. 3. Calibration curves for six PAHs by applying HPLC/FLD (Nos. 1, 2, 3, 4, 5, 6) and for indeno(1,2,3-cd)pyrene (No. 7) by application of GC/MS. 
Table 6. The results obtained by the method based on the Standard Norm.

\begin{tabular}{|l|c|c|}
\hline \multicolumn{1}{|c|}{ Compounds } & Recovery \% & SD \\
\hline Pyrene & 94 & 13.0 \\
\hline Benzo(a)anthracene & 94 & 6.8 \\
\hline Benzo(b)fluoranthene & 88 & 9.5 \\
\hline Benzo(k)fluoranthene & 82 & 13.0 \\
\hline Benzo(a)pyrene & 75 & 12.0 \\
\hline Indeno(1,2,3-cd)pyrene & 83 & 12.0 \\
\hline
\end{tabular}

\section{Results and Discussion}

\section{Extraction Method Validation}

On the basis of the results obtained, the optimum method of the PAH extraction from soil was found. ASE with the use of the dichloromethane-acetone mixture (1:1 ratio) was the chosen method. From the basic standard solution, six working standard solutions were prepared by dilution to the concentrations of 100,150, 200, 300, 400, and $500 \mu \mathrm{g} / \mathrm{l}$. A chromatographic analysis was performed with the use of HPLC/FLD and GC/MS. For each of the compounds examined, an analytical curve (Fig. 3) as well as detection and determination limits were determined (Table 7). The PAH chromatograms in the CRM141 material obtained by HPLC/FLD and GC/MS are presented in Fig. 4.

\section{PAH in the New Reference Material}

The PAHs were extracted from soil with the use of ASE. The extraction was performed for natural soil, which is the matrix for both the new reference material and the candidate for a new, certified reference material (Fig. 5). By HPLC/FLD, it is possible to quantitatively determine five compounds (pyrene, benzo(a)anthracene, benzo(b)fluoranthene, benzo(k)fluoranthene, benzo(a)pyrene) in the new reference material. Due to interferants which elute with indeno(1,2,3-cd)pyrene, it is not possible to analyse it qualitatively with liquid chromatographic methods. GC/MS was applied in the analysis of this compound (the candidate for the new reference material) in soil (Fig. 6). The recovery was $114 \%$ and the repeatability was $\mathrm{SD}=4.1$. The findings are shown in Table 8 .

Table 7. Limit of detection and limit of quantification for six compounds (values in parentheses were obtained for GC/MS).

\begin{tabular}{|l|c|c|}
\hline \multicolumn{1}{|c|}{ Compounds } & LOD $[\mu \mathrm{g} / \mathrm{l}]$ & LOQ $[\mu \mathrm{g} / \mathrm{l}]$ \\
\hline Pyrene & 5.23 & 15.7 \\
\hline Benzo(a)anthracene & 5.56 & 16.7 \\
\hline Benzo(b)fluoranthene & 4.58 & 13.7 \\
\hline Benzo(k)fluoranthene & 4.67 & 14.0 \\
\hline Benzo(a)pyrene & 5.49 & 16.5 \\
\hline Indeno(1.2.3-cd)pyrene & $4.95(26.5)$ & $14.9(79.4)$ \\
\hline
\end{tabular}
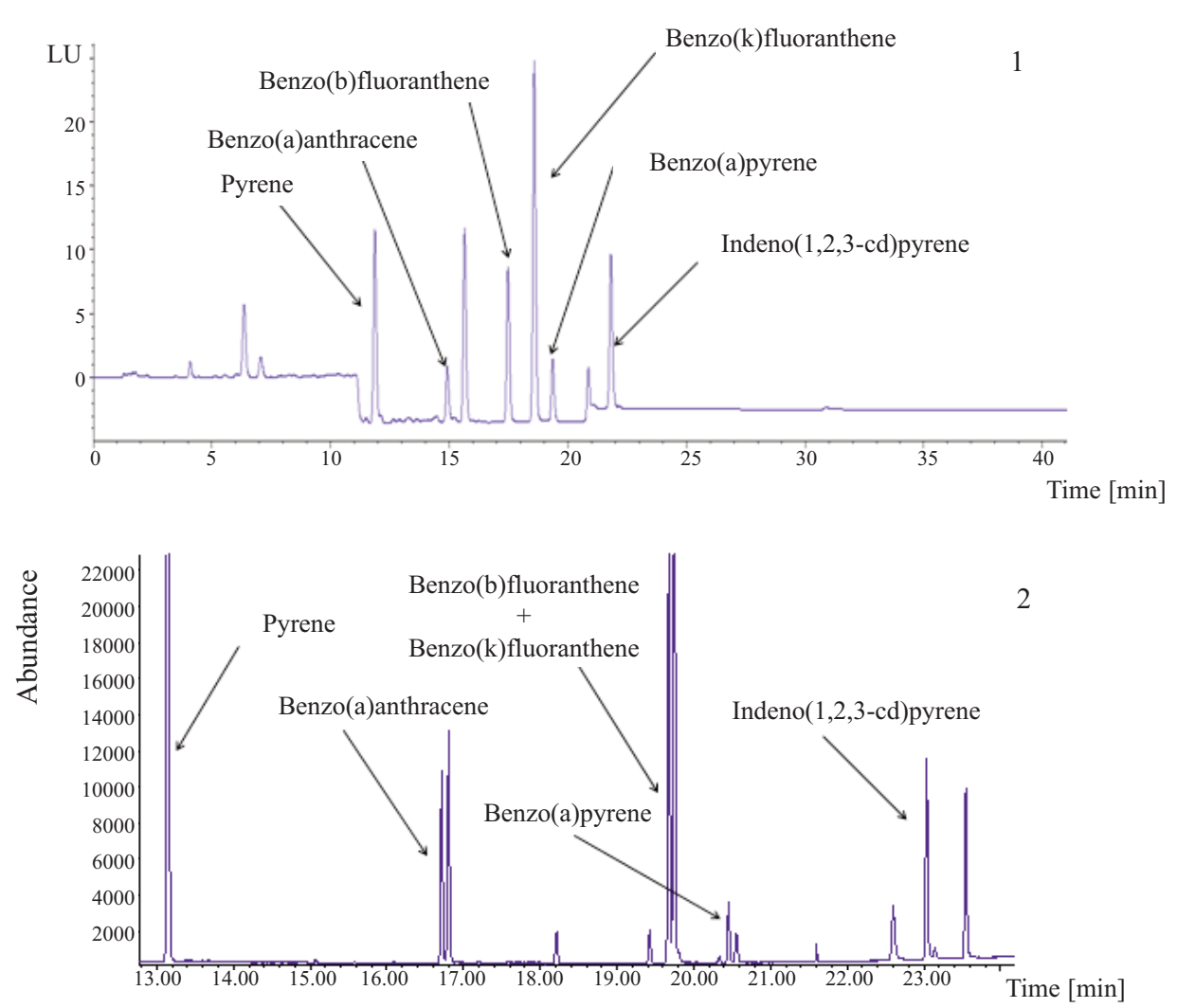

Fig. 4. Chromatogram of PAH in CRM141 for HPLC (1) and GC (2) analysis. 
Table 8. Concentrations of six PAHs in new certified reference material's candidate and in natural soil.

\begin{tabular}{|c|c|c|c|c|c|c|}
\hline \multirow{3}{*}{ Compounds } & \multicolumn{2}{|c|}{ Natural soil } & \multicolumn{4}{|c|}{ Fortified soil } \\
\hline & \multirow{2}{*}{$\begin{array}{c}\text { Concentration } \\
{[\mu \mathrm{g} / \mathrm{kg}]}\end{array}$} & \multirow{2}{*}{ SD } & \multicolumn{2}{|l|}{ HPLC/FLD } & \multicolumn{2}{|l|}{ GC/MS } \\
\hline & & & Concentration $[\mu \mathrm{g} / \mathrm{kg}]$ & SD & Concentration $[\mu \mathrm{g} / \mathrm{kg}]$ & SD \\
\hline Pyrene & 500 & 60 & 4638 & 162 & 4765 & 94 \\
\hline Benzo(a)anthracene & 313 & 25 & 533 & 37 & 487 & 42 \\
\hline Benzo(b)fluoranthene & 410 & 36 & 625 & 39 & \multirow{2}{*}{1016} & \multirow{2}{*}{34} \\
\hline Benzo(k)fluoranthene & 277 & 58 & 310 & 28 & & \\
\hline Benzo(a)pyrene & 446 & 51 & 545 & 48 & 499 & 46 \\
\hline Indeno(1,2,3-cd)pyrene & 329 & 67 & 1557 & 64 & 561 & 51 \\
\hline
\end{tabular}
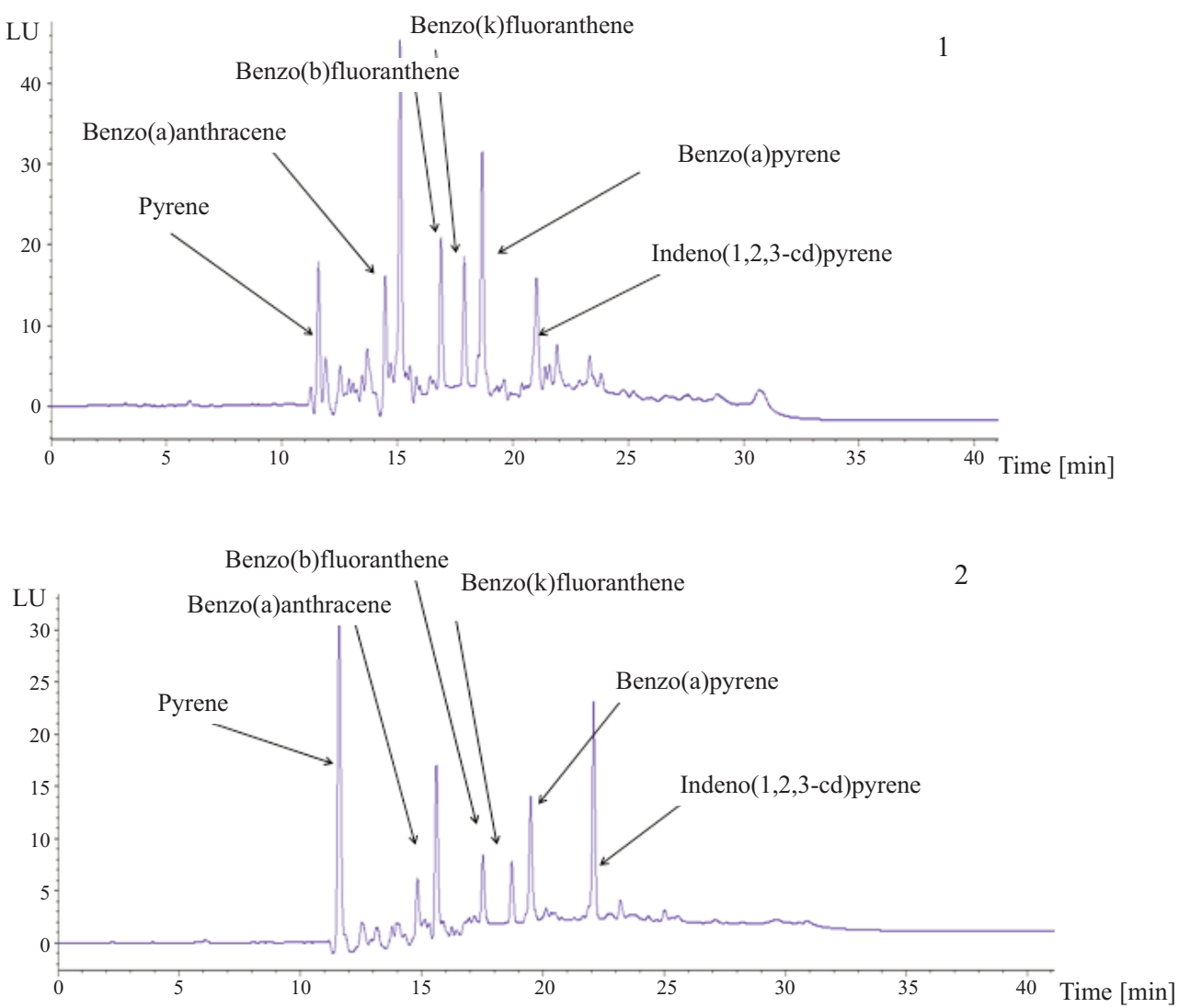

Fig. 5. Chromatograms of PAH in natural soil (1) and in new CRM (2) for HPLC analysis.

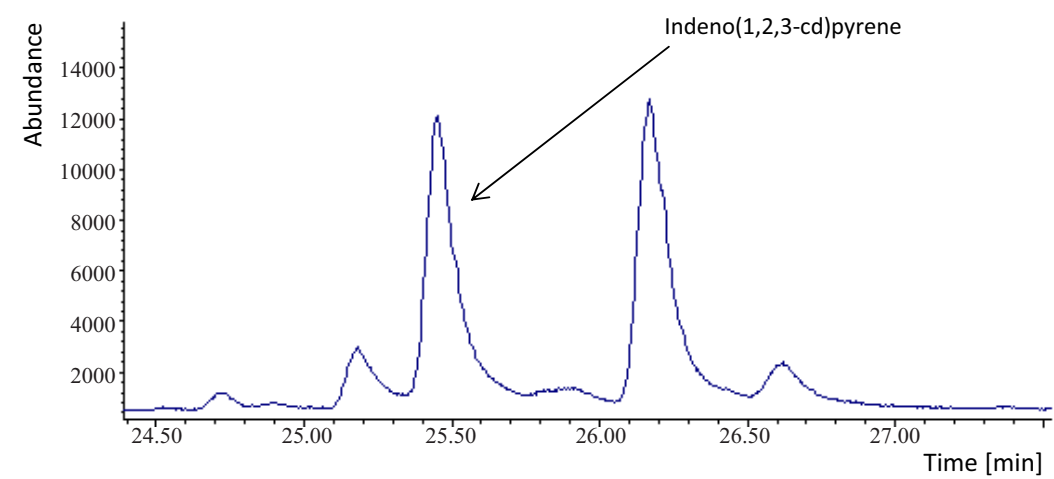

Fig. 6. Chromatogram of indeno(1,2,3-cd)pyrene in new certified reference material for GC analysis. 


\section{Conclusions}

The ASE extraction method with the use of the dichloromethane-acetone mixture (1:1 ratio) was found to be the optimum method of the PAH extraction from soil. It is characterized by the highest recovery and, at the same time, traceability. The method is quick and requires the use of a small amount of the sample. The sample preparation process for extraction is also time-efficient. Preparing the sample for analysis with the use of HPLC/FLD and GC/MS is simultaneous. It is cost-efficient due to smaller amounts of the solvent needed for the analysis and shorter total procedure time.

The detection and determination limits found are low, which allows for the determination of the PAH in a broad range of concentration values. It is possible to perform both qualitative as well as quantitative analysis. The analytical curves exhibited good linearity throughout the whole working range. The content of particular compounds from the PAH group in the newly developed reference material is very high. The material will not only turn out to be very useful in routine laboratory tests but also constitute a reference when examining soil collected from areas affected by ecocatastrophes or struggling with environmental contamination by the PAH.

\section{Acknowledgements}

This project was financed in the framework of the grant, "Production and attestation of new types of reference materials crucial for achieving European accreditation for Polish industrial laboratories (MODAS)," by the National Center for Research and Development, No. INNOTECH-K1/ IN1/43/158947/NCBR/12.

This paper was supported from the budget of Kuyavia and Pomerania and the European Regional Development Fund under the ROP for the years 2007-2013: project No. RPKP.05.04.00-04-003/13.

\section{References}

1. INTERNATIONAL ORGANIZATION FOR STANDARDIZATION (Geneva, Switzerland), Accuracy (trueness and precision) of Measurement Methods and Results, ISO-5725 Parts 1-6, 1994. Guide to the Expression of Uncertainty in Measurement, 1993. Statistics - Vocabulary and Symbols, ISO-3534, 1993.
2. INTERNATIONAL ORGANIZATION FOR STANDARDIZATION (Geneva, Switzerland), General requirements for the competence of testing and calibration laboratories, ISO/IEC 17025, 2005.

3. INTERNATIONAL ORGANIZATION FOR STANDARDIZATION (Geneva, Switzerland) Quality system gudelines for the production of reference materials, ISO/IEC Guide 34, 1996; Terms and definitions used in connection with reference materials, ISO Guide 30, 1992; Contents of certificates of reference materials, ISO Guide 31, 1981; Certification of reference materials: general and statistical principles, ISO/IEC Guide 35, 1989; Calibration in analytical chemistry and use of certified reference materials, ISO Guide 32, 1997; Uses of Certified Reference Materials, Revised ISO Guide 33, 2000.

4. ITOH N., INAGAKI K., NARUKAWA T., AOYAGI Y., NARUSHIMA I., KOGUCHI M., NUMATA M. Certified reference material for quantification of polycyclic aromatic hydrocarbons and toxic elements in tunnel dust (NMIJ CRM 7308-a) from the National Metrology Institute of Japan. Anal. Bioanal. Chem. 401, 2909, 2011.

5. NARUKAWA T., INAGAKI K., ZHU Y., KUROIWA T., NARUSHIMA I., CHIBA K., HIOKI A. Preparation and certification of Hijiki reference material, NMIJ CRM 7405a, from the edible marine algae hijiki (Hizikia fusiforme). Anal. Bioanal. Chem. 402, 1713, 2012.

6. MCCARRON P., EMTEBORG H., GIDDINGS S. D., WRIGHT E., QUILLIAM M. A. A mussel tissue certified reference material for multiple phycotoxins. Part 3: homogeneity and stability. Anal. Bioanal. Chem. 400, 847, 2011.

7. KUPIEC K., KONIECZKA P., NAMIEŚNIK J. Prospects for the production, research and utilization of reference materials. Crit. Rev. Anal. Chem. 39, 311, 2009.

8. SŁOMIŃSKA M., KONIECZKA P., NAMIEŚNIK J. Standard gas mixtures - indispensable reference materials in the analysis of gaseous media. TRAC-Trend. Anal. Chem. 29, 419, 2010.

9. SŁOMIŃSKA M., KONIECZKA P., NAMIEŚNIK J. New developments in preparation and use of standard gas mixtures. TRAC-Trend. Anal. Chem. 62, 135, 2014.

10. YAMAGUCHI Ch., LEE W.-Y. A cost effective, sensitive, and environmentally friendly sample preparation method for determination of polycyclic aromatic hydrocarbons in solid samples. J. Chromatogr. A 1217, 6816, 2010.

11. FABBRI D., ROMBOLÁ A. G., TORRI C., SPOKAS K. A. Determination of polycyclic aromatic hydrocarbons in biochar and biochar amended soil. J. Anal. Appl. Pyrol. 103, 60, 2013.

12. MA X., RAN Y., GONG J., CHEN D. Sequential accelerated solvent extraction of polycyclic aromatic hydrocarbons with different solvents: Performance and implication. J. Environ. Qual. 39, 2079, 2010.

13. YANG Y., LIGOUIS B., PIES C., ACHTEN CH., HOFMANN T. Identification of carbonaceous geosorbents for PAHs by organic petrography in river floodplain soils. Chemosphere 71, 2158, 2008. 